\title{
Buck-Boost/Forward Hybrid Converter for PV Energy Conversion Applications
}

\author{
Sheng-Yu Tseng, Chien-Chih Chen, and Hung-Yuan Wang \\ Department of Electrical Engineering, Chang-Gung University, 259 Wen-Hwa 1st Road, Tao-Yuan 333, Taiwan \\ Correspondence should be addressed to Sheng-Yu Tseng; sytseng@mail.cgu.edu.tw
}

Received 16 August 2013; Revised 28 February 2014; Accepted 28 February 2014; Published 7 April 2014

Academic Editor: Ismail H. Altas

Copyright (c) 2014 Sheng-Yu Tseng et al. This is an open access article distributed under the Creative Commons Attribution License, which permits unrestricted use, distribution, and reproduction in any medium, provided the original work is properly cited.

\begin{abstract}
This paper presents a charger and LED lighting (discharger) hybrid system with a PV array as its power source for electronic sign indicator applications. The charger adopts buck-boost converter which is operated in constant current mode to charge leadacid battery and with the perturb and observe method to extract maximum power of PV arrays. Their control algorithms are implemented by microcontroller. Moreover, forward converter with active clamp circuit is operated in voltage regulation condition to drive LED for electronic sign applications. To simplify the circuit structure of the proposed hybrid converter, switches of two converters are integrated with the switch integration technique. With this approach, the proposed hybrid converter has several merits, which are less component counts, lighter weight, smaller size, and higher conversion efficiency. Finally, a prototype of LED driving system under output voltage of $10 \mathrm{~V}$ and output power of $20 \mathrm{~W}$ has been implemented to verify its feasibility. It is suitable for the electronic sign indicator applications.
\end{abstract}

\section{Introduction}

In recent years, light emitting diodes (LEDs) are becoming more prevalent in a wide application. Due to material advances over the past few decades, efficiencies of LEDs have increased many times [1], and their applications have rapidly grown for automotive taillights, LCD back lights, traffic signals, and electronic signs [2,3]. Moreover, serious greenhouse effect and environmental pollution caused by overusing fossil fuels have disturbed the balance of global climate. In order to reduce emission of exhausted gases, zeroemission renewable energy sources have been rapidly developed. One of these sources is photovoltaic (PV) arrays, which is clean and quiet and an efficient method for generating electricity. As mentioned above, this paper proposes an LED driving system, which adopts the PV arrays for electronic sign applications.

In electronic sign applications using PV arrays, the power system will inevitably need batteries for storing energy during the day and for releasing energy to LED lighting during the night. Therefore, it needs a charger and discharger (LED driving circuit), as shown in Figure 1. Since the proposed power system belongs to the low power level applications, buck, boost, buck-boost, flyback, or forward converter is more applied to the proposed one [4-12]. In these circuit structures, according to the relationships among PV output voltage $V_{\mathrm{PV}}$, battery voltage $V_{B}$, and output voltage $V_{O}$, the proposed hybrid converter can choose functions, which are of step-up and -down simultaneously as the charger or discharger for a wider application. Due to the previously described reasons, the charger of the proposed one adopts buck-boost converter and the discharger uses forward converter. Moreover, since forward converter exits two problems, which are the energies trapped in leakage inductor and magnetizing inductor of transformer $T_{f}$, it needs a snubber or circuit to recover these energies. Therefore, forward converter can use an active clamp circuit to solve these problems. In order to simplify the proposed hybrid converter and increase its conversion efficiency, a bidirectional buck-boost converter and active clamp forward converter are used, as shown in Figure 2. Since charger and discharger (LED driving circuit) of the proposed hybrid converter are operated in complement and they use switch $S_{1}$ to control their operational states, inductor $L_{1}$ of buck-boost converter and magnetizing inductor $L_{m}$ of transformer $T_{f}$ can be merged. Therefore, switches of the bidirectional buck-boost converter and active clamp forward 


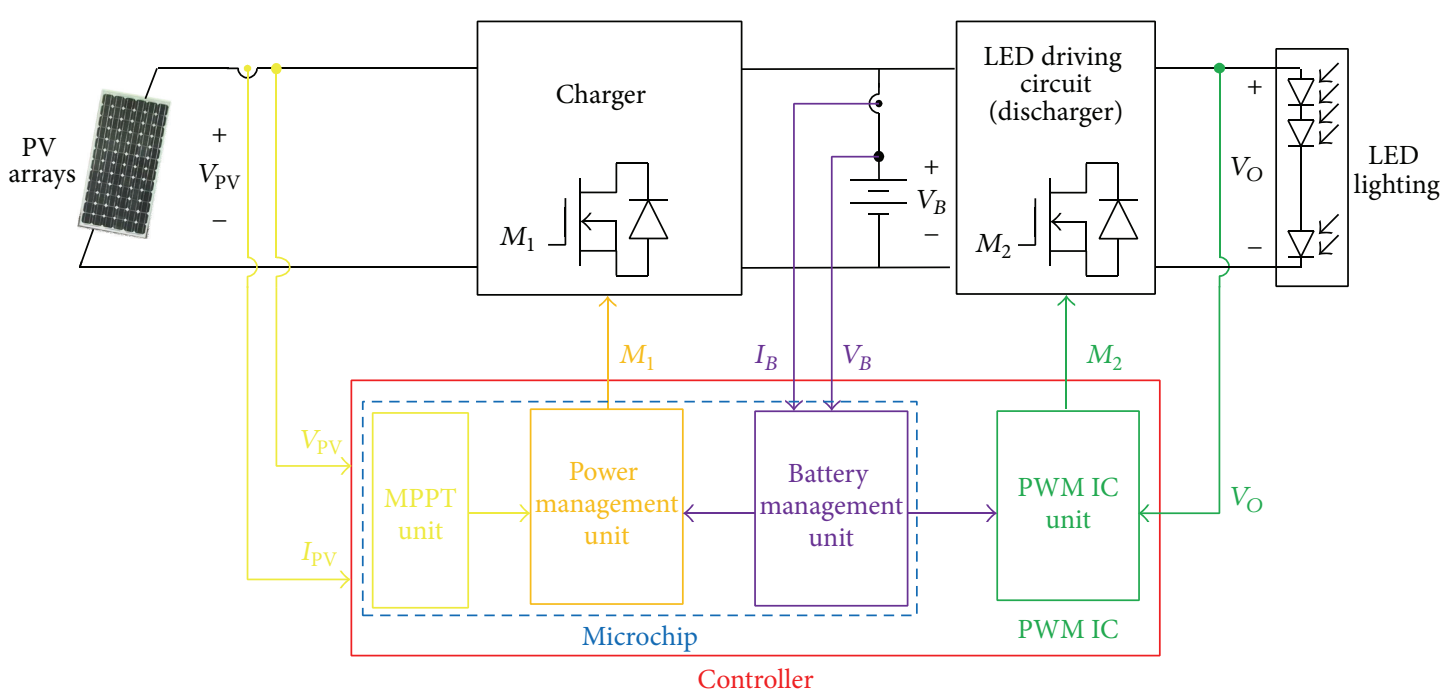

FIGURE 1: Block diagram of the proposed hybrid converter for electronic sign applications.



FIGURE 2: Schematic diagram of the hybrid converter for electronic sign applications.

converter are integrated with synchronous switch technique [13] to reduce their component counts, as shown in Figure 3. With this circuit structure, the proposed one can yield higher efficiency, reduce weight, size, and volume and increase the discharging time of battery under the same storing energy, significantly.

The proposed hybrid converter using PV arrays supplies power to LED lighting for electronic sign applications. The proposed one includes charger and discharger. Since the proposed one uses PV arrays as its power source, it must be operated at the maximum power point (MPP) of PV arrays to extract its maximum power. Many maximum power point tracking (MPPT) methods of PV arrays have been proposed [14-21]. They are, respectively, power matching $[14,15]$, curve-fitting $[16,17]$, perturb-and-observe $[18,19]$, and incremental conductance $[20,21]$ methods. Since power matching method requires a specific insolation condition or load, it will limit its applications. MPPT using curve-fitting technique needs prior establishment characteristic curve of $\mathrm{PV}$ arrays. It cannot predict the characteristics including other factors, such as aging, temperature, and a possible breakdown of individual cell. The incremental conductance technique requires an accurate mathematical operation. Its controller is more complex and higher cost. Due to a simpler control and lower cost of perturb and observe method, the proposed hybrid converter adopts the perturb and observe method to implement MPPT.

For electronic sign applications using LED, the power system needs battery to store energy during day and to discharge energy for driving LED during night. In order to generate better performances of battery charging, many battery charging methods have been proposed. They are constant trickle current (CTC), constant current (CC), and CC and constant-voltage (CC-CV) hybrid charge methods [22]. Among these methods, the CTC charging method needs a larger charging time. Battery charging using CC-CV method requires to sense battery current and voltage, resulting in a more complex operation and higher cost. Due to a simpler controller of battery charger using CC charging method, it is adopted in the proposed hybrid converter. According to description above, the proposed hybrid converter uses the perturb and observe method to track MPP of PV arrays and 


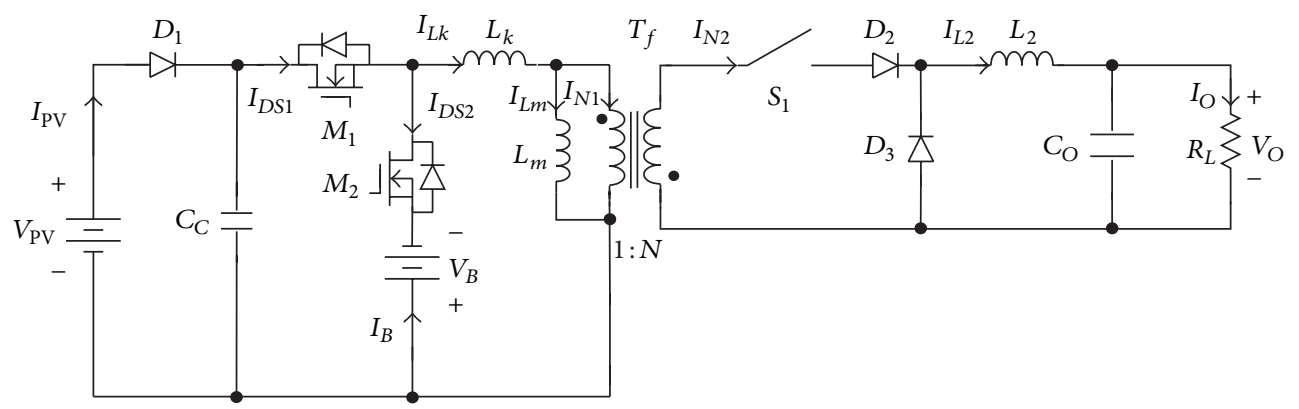

FIGURE 3: Schematic diagram of the proposed hybrid converter for electronic sign applications.

adopts the CC charging method to simplify battery charging. All overall power system can achieve battery charging and LED driving.

\section{Circuit Structure Derivation of the Proposed Hybrid Converter}

The hybrid converter consists of a bidirectional buck-boost and active clamp forward converter, as shown in Figure 2. Due to complementary operation between two converters, two switch pairs of $\left(M_{1}, M_{4}\right)$ and $\left(M_{2}, M_{3}\right)$ can be operated in synchronous. It will do not affect the operation of the proposed original converter. Since switch pairs of $\left(M_{2}, M_{3}\right)$ has a common node, they meet the requirements of switch integration technique [11]. According to principle of switch integration technique, switches $M_{2}$ and $M_{3}$ can be merged, as shown in Figure 4(a). Since charger and LED driving circuit (discharger) are operated in complementary, switch $M_{2}$ and $M_{3}$ are also regarded as an independent operation. Therefore, voltages across switches $M_{2}$ and $M_{3}$ are the same value in each operation state. Diode $D_{F 231}$ and $D_{F 232}$ can be removed, while diode $D_{B 231}$ and $D_{B 232}$ can be shorted, as shown in Figure 4(b). In Figure 4(b), since $L_{K} \ll L_{m}$, $L_{K}$ can be neglected. The inductor $L_{1}$ and magnetizing $L_{m}$ are connected in parallel. Although features of inductors $L_{1}$ and $L_{m}$ are different, their design rules are to avoid them to operate in saturation condition. Therefore, they can be merged as inductor $L_{1 m}$, as shown in Figure 4(c).

From Figure 4(c), it can be seen that switch $M_{1}$ and $M_{4}$ have a common node. They can use switch integration technique to combine them, as shown in Figure 4(d). Since voltages across $M_{1}$ and $M_{4}$ are the same values, diodes $D_{B 141}$ and $D_{B 142}$ are shorted and diodes $D_{F 141}$ and $D_{F 142}$ can be removed, as shown in Figure 4(e). From Figure 4(e), it can be found that capacitors $C_{1}$ and $C_{2}$ are connected in parallel. They can be integrated as capacitor $C_{C}$, as illustrated in Figure 4(f). To simplify symbols of components illustrated in Figure 4(f), component symbols will be renamed, as shown in Figure 3. Note that switch $S_{1}$ can be operated by manual or automatic method to control the operational states of the proposed hybrid converter.

Buck-boost and forward converters are combined to form the proposed hybrid converter. Since operation of buckboost converter is the same as the conventional buck-boot converter, its operational principle is described in [8]. It will not be described in this paper. The forward converter with the active clamp circuit recovers the energies stored in magnetizing and leakage inductors of transformer $T_{f}$ and achieves zero-voltage switch (ZVS) at turn-on transition for switches $M_{1}$ and $M_{2}$. It operational mode can be divided into 9 modes and their Key waveforms are illustrated in Figure 5, since their operational modes are similar to those modes of the conventional converter illustrated in [23]. It is also not described in this paper.

\section{Design of the Proposed Hybrid Converter}

The proposed hybrid converter consists of buck-boost converter and active clamp forward converter. Since switches and inductors in two converters are integrated with the synchronous switch technique, design of the proposed one must satisfy requirements of each converter. Since design of the active clamp forward converter is illustrated in [23], buckboost converter is only analyzed briefly in the following.

3.1. Buck-Boost Converter. Since buck-boost converter is regarded as the battery charger under constant current charging. Its design consideration is to avoid a completely saturation of inductor. Therefore, duty ratio $D_{11}$ and inductor $L_{m}$ are analyzed in the following.

3.1.1. Duty Ratio $D_{11}$. Within charging mode, since battery voltage $V_{B}$ is regarded as a constant voltage during a switching cycle of the proposed hybrid converter, maximum duty ratio $D_{11(\max )}$ of the proposed one can be determined by voltsecond balance of inductor $L_{m}$. Its relationship is expressed as

$$
V_{\mathrm{PV}(\min )} D_{11(\max )} T_{s}+\left(-V_{B(\max )}\right)\left(1-D_{11(\max )}\right) T_{s}=0,
$$

where $V_{\mathrm{PV}(\min )}$ is the minimum output voltage of $\mathrm{PV}$ arrays, $V_{B(\max )}$ is the maximum voltage across battery, and $T_{s}$ represents the period of the proposed hybrid converter. From (1), it can be found that $D_{11(\max )}$ can be illustrated by

$$
D_{11(\max )}=\frac{V_{B(\max )}}{V_{\mathrm{PV}(\min )}+V_{B(\max )}} .
$$




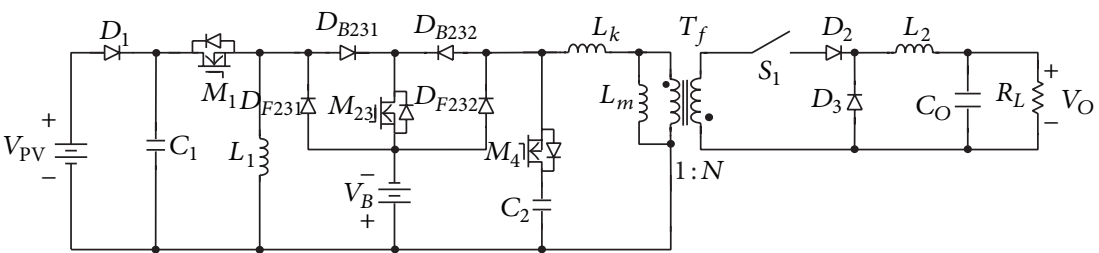

(a)

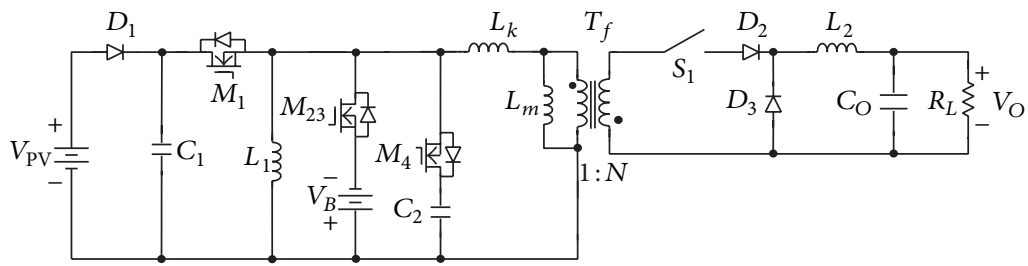

(b)

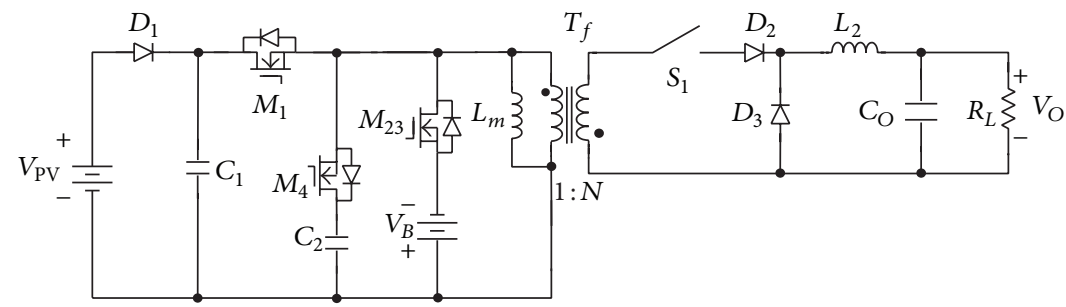

(c)

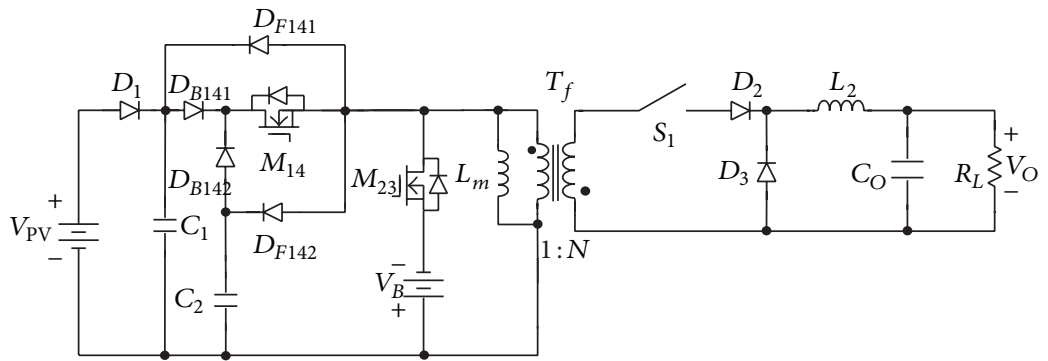

(d)

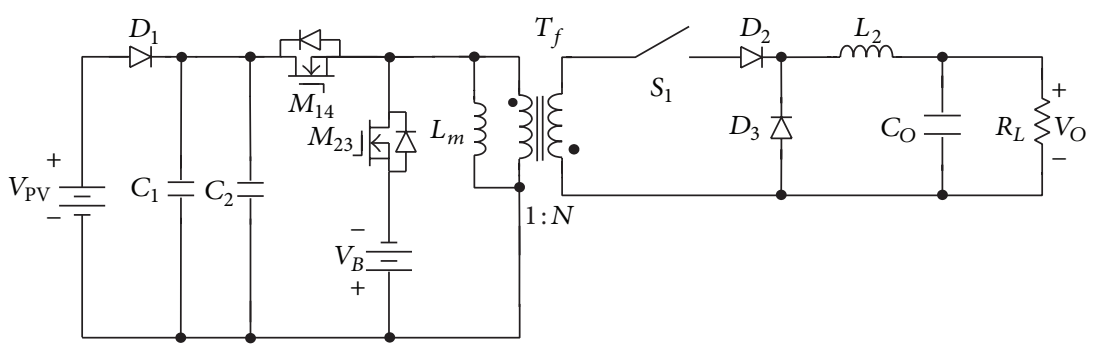

(e)

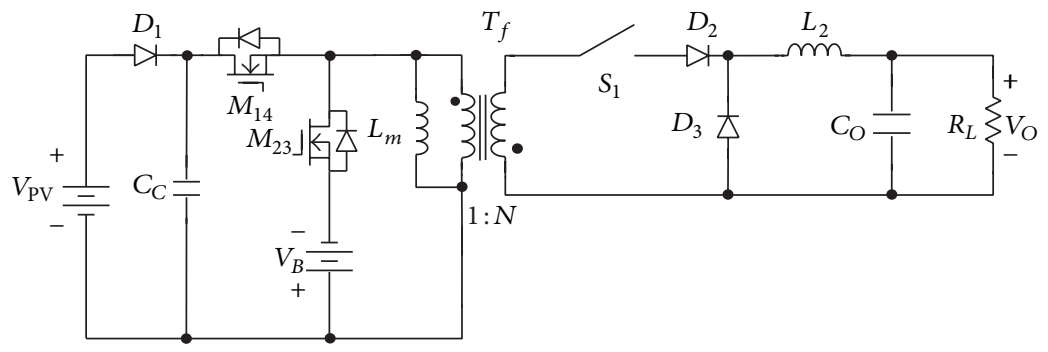

(f)

FIgURE 4: Derivation of the proposed hybrid converter for battery charger. 


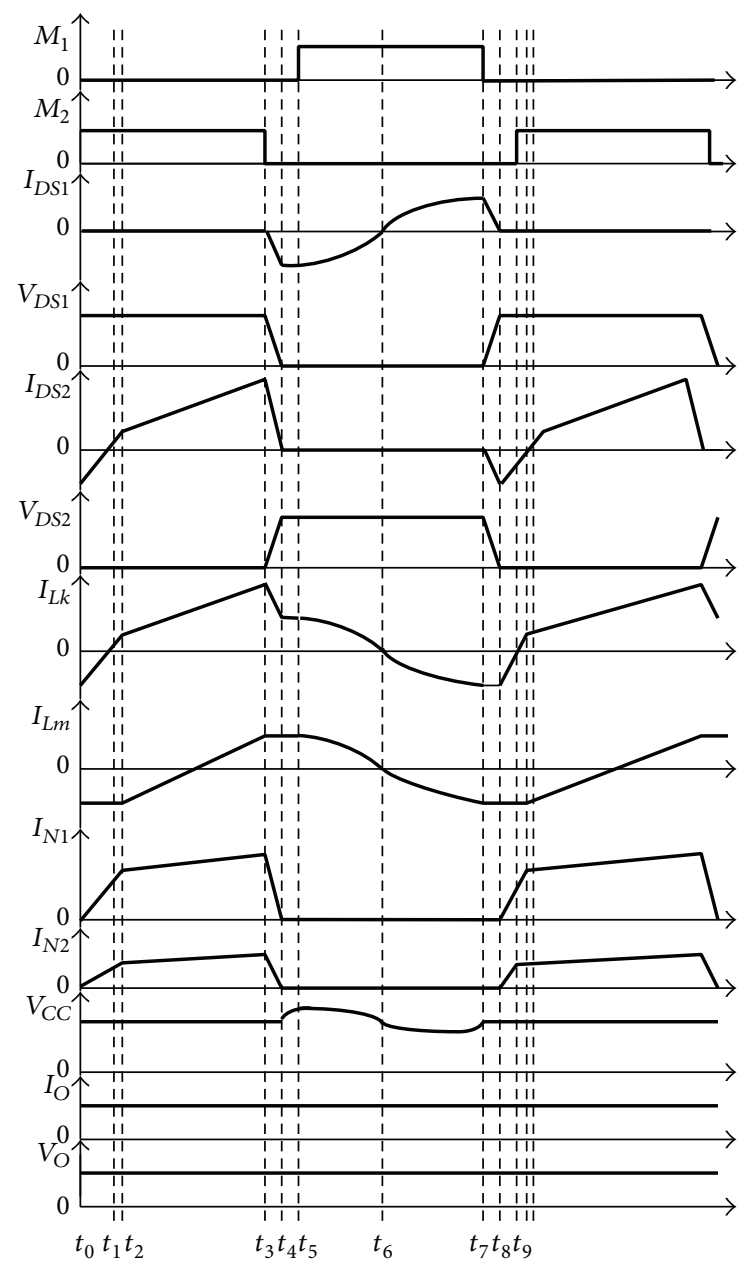

FIGURE 5: Key waveforms of forward converter with active clamp circuit over one switching cycle.

Moreover, transfer ratio $M_{11(\max )}$ can be also determined as follows:

$$
M_{11(\max )}=\frac{D_{11(\max )}}{1-D_{11(\max )}} .
$$

When type of battery is chosen, its maximum charging current $I_{B(\max )}$ is also determined. The charging current $I_{B}$ can be changed from its maximum charging current $I_{B(\max )}$ to 0 by variation duty ratio $D_{11}$ of switch $M_{1}$.

3.1.2. Inductor $L_{m}$. Since the proposed hybrid converter is operated in CCM to obtain the maximum charging current $I_{B(\max )}$, its conceptual waveforms of inductor current $I_{L m}$ and charging current $I_{B}$ are illustrated in Figure 6. If the proposed one is operated in the boundary of discontinuous conduction mode (DCM) and CCM, the charging current $I_{B}$ is expressed by

$$
I_{B(\mathrm{av})}=\frac{\left(1-D_{11}\right)^{2} V_{B} T_{s}}{2 L_{m B}},
$$

where $L_{m B}$ is the inductance $L_{m}$ at the boundary condition. According to (4), variation of duty ratio $D_{11}$ can obtain

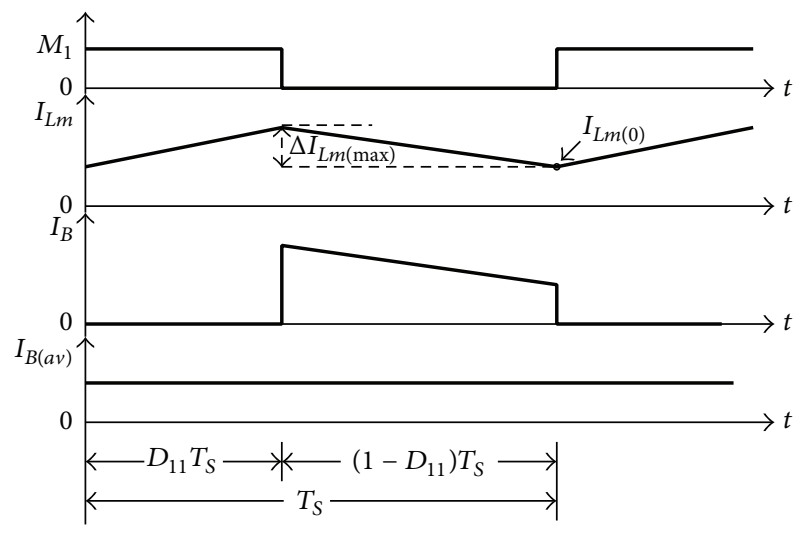

Figure 6: Conceptual waveforms of inductor current $I_{L m}$ and charging current $I_{B}$ in buck-boost converter.

a different charging current $I_{B}$. In general, the maximum charge current $I_{B(\text { av } \max }$ occurs at the maximum battery voltage $V_{B(\max )}$ and the maximum output voltage $V_{\mathrm{PV}(\max )}$ of PV arrays. Therefore, the boundary inductor $L_{m B}$ can be determined by

$$
I_{B(\mathrm{av}) \max }=\frac{\left(1-D_{11 B}\right)^{2} V_{B(\max )} T_{s}}{2 L_{m B}},
$$

where $D_{11 B}$ is duty ratio of switch $M_{1}$ under $V_{B(\max )}$ and $V_{\mathrm{PV}(\max )}$. From (5), it can be found that the maximum boundary inductor $L_{m B(\max )}$ can be expressed as

$$
L_{m B(\max )}=\frac{\left(1-D_{11 B}\right)^{2} V_{B(\max )} T_{s}}{I_{B(\mathrm{av}) \max }} .
$$

Since the proposed hybrid converter is operated in CCM, inductor $L_{m}$ must be greater than $L_{m B(\max )}$. Therefore, when $V_{\mathrm{PV}(\max )}, V_{B(\max )}, I_{B(\text { av) max }}$, and $T_{s}$ are specified, the minimum inductance $L_{m(\min )}\left(=L_{m B(\max )}\right)$ can be determined.

In order to avoid the core of transformer $T_{f}$ operated in saturation state, the working flux density $B_{\max }$ must be less than the saturation flux density $B_{\text {sat }}$ of core. Since $B_{\max }$ is proportional to the maximum inductor current $I_{L m \text { (peak) }}$, $I_{L m \text { (peak) }}$ must be first determined. In Figure 6, $I_{L m \text { (peak) }}$ can be expressed as

$$
I_{L m(\text { peak })}=I_{L m(0)}+\Delta I_{L m(\max )} \text {, }
$$

where $I_{L m(0)}$ is the initial value of inductor current $I_{L m}$ operated in CCM and $\Delta I_{L m(\max )}$ represents its maximum variation value. In general, its maximum value $\Delta I_{L m(\max )}$ can be determined by

$$
\Delta I_{L m(\max )}=\frac{V_{\mathrm{PV}(\max )} D_{11 R} T_{s}}{L_{m}}
$$


where $D_{11 R}$ represents the duty ratio of switch $M_{1}$ under $V_{\mathrm{PV}(\max )}$ and $V_{B(\max )}$. Furthermore, the maximum charging current $I_{B(\text { av) max }}$ can be expressed as

$$
\begin{aligned}
I_{B(\text { av }) \max } & =\frac{\left(1-D_{11 R}\right)}{2}\left(I_{L m(\text { peak })}+I_{L m(0)}\right) \\
& =\frac{\left(1-D_{11 R}\right)}{2}\left(2 I_{L m(0)}+\frac{V_{\mathrm{PV}(\max )} D_{11 R} T_{s}}{L_{m}}\right) .
\end{aligned}
$$

From (9), the initial value $I_{L m(0)}$ can be determined as follows:

$$
I_{L m(0)}=\frac{I_{B(\text { av }) \max }}{1-D_{11 R}}-\frac{V_{\mathrm{PV}(\max )} D_{11 R} T_{s}}{2 L_{m}} .
$$

From (7), (8), and (10), $I_{L m \text { (peak) }}$ can be denoted as

$$
I_{L m(\text { peak })}=\frac{I_{B(\text { av }) \max }}{1-D_{11 R}}+\frac{V_{\mathrm{PV}(\max )} D_{11 R} T_{s}}{2 L_{m}} .
$$

According to datasheet of core which is supplied by core manufacturer, the number of turns $N_{1}$ on the primary side of transformer $T_{f}$ can be obtained by

$$
N_{1}=\sqrt{\frac{L_{m}}{A_{L}}}
$$

where $A_{L}$ represents $\mathrm{nH}$ per turns ${ }^{2}$. That is, $L_{m}=N_{1}^{2} A_{L}$. By applying Faraday's law, $B_{\max }$ can be determined as

$$
B_{\max }=\frac{L_{m} I_{L m(\text { peak })} \times 10^{4}}{N_{1} A_{c}},
$$

where $A_{c}$ is the effective cross-section area of the transformer core. In order to avoid saturation condition of core, $B_{\max }$ must be less than saturation flux density $B_{\text {sat }}$ of core.

\section{Configuration of the Proposed PV Hybrid Converter}

Since the proposed PV power system includes charger and discharger and adopts PV arrays as its power source, its circuit structure and control algorithm are described in the following.

4.1. Circuit Structure of the Proposed PV Power System. The proposed PV power system consists of battery charger, LED driving circuit (discharger), and controller, as shown in Figure 1. The battery charger and LED driving circuit using buck-boost and active clamp forward hybrid converter are shown in Figure 3. In addition, controller adopts microchip and PWM IC for managing battery charging and LED driving circuit. The microchip is divided into 3 units (MPPT, power management, and battery management units) to implement

\begin{tabular}{|c|c|}
\hline Symbol & Definition \\
\hline$\overline{V_{\mathrm{PV}}}$ & Output voltage of PV arrays \\
\hline$I_{\mathrm{PV}}$ & Output current of PV arrays \\
\hline$P_{P}$ & Maximum power of PV arrays \\
\hline$P_{B}$ & Charging power of battery $\left(P_{B}=V_{B} I_{B}\right)$ \\
\hline$P_{B(\max )}$ & $\begin{array}{l}\text { Maximum charging power of battery } \\
\left(P_{B(\max )}=V_{B} I_{B(\max )}\right)\end{array}$ \\
\hline$I_{B}$ & Charging current of battery \\
\hline$V_{B}$ & Battery voltage \\
\hline$V_{O}$ & Output voltage of forward converter \\
\hline$I_{O}$ & Output current of forward converter \\
\hline$V_{B(\max )}$ & Maximum voltage of battery \\
\hline$V_{B(\min )}$ & Minimum voltage of battery \\
\hline$V_{\mathrm{O}(\max )}$ & $\begin{array}{l}\text { Maximum output voltage of forward } \\
\text { converter }\end{array}$ \\
\hline$I_{O(\max )}$ & $\begin{array}{l}\text { Maximum output current of forward } \\
\text { converter }\end{array}$ \\
\hline$I_{B(\max )}$ & Maximum current of battery \\
\hline$V_{\text {ref }}$ & $\begin{array}{l}\text { Reference voltage for obtaining the } \\
\text { desired output voltage } V_{O}\end{array}$ \\
\hline$I_{C}$ & $\begin{array}{l}\text { Current command for obtaining the } \\
\text { desired charging current } I_{B}\end{array}$ \\
\hline$S_{M}$ & $\begin{array}{l}\text { Control signal of operational mode }\left(S_{M}=\right. \\
0 \text {, battery charging; } S_{M}=1 \text {, LED driving) }\end{array}$ \\
\hline$S_{n}$ & $\begin{array}{l}\text { Insolation level judgment }\left(S_{n}=1 \text {, low }\right. \\
\text { insolation level; } S_{n}=0 \text {, high insolation } \\
\text { level) }\end{array}$ \\
\hline$V_{f}$ & Feedback signal of PWM IC \\
\hline$V_{e}$ & Error value \\
\hline$G_{1}, G_{2}$ & pwM signals \\
\hline$M_{1}, M_{2}$ & Gate signals of switches $M_{1}$ and $M_{2}$ \\
\hline
\end{tabular}
MPPT of PV arrays and battery charging. The PWM IC is used to regulate output voltage of LED driving circuit. In the microchip of the controller, the MPPT unit senses PV voltage $V_{\mathrm{PV}}$ and current $I_{\mathrm{PV}}$ to achieve MPPT, which adopts
TABLE 1: Parameter definitions of control signals shown in Figure 4.

perturb and observe method. The battery management unit acquires battery voltage $V_{B}$ and current $I_{B}$ for implementing CC charging of battery. Since the proposed hybrid converter is required to match MPPT of PV arrays and CC charging mode, the power management unit can manage the power flow between PV arrays and battery, depending on the relationship of the generated power of $\mathrm{PV}$ arrays and the required power of battery charging. All of protections are implemented by microchip. The protections include overcurrent and overvoltage protections of the proposed hybrid converter and undercharge and overcharge of battery. Therefore, the proposed one can achieve the optimal utility rate of $\mathrm{PV}$ arrays and a better performance of battery charging.

4.2. Control Algorithm of the Proposed Hybrid Converter. In Figure 1, the controller of the proposed hybrid converter includes microchip and PWM IC to achieve battery charging and LED driving. In order to implement battery charging and LED driving, block diagram of the hybrid converter is shown in Figure 7. In Figure 7, control signals are defined in Table 1. 


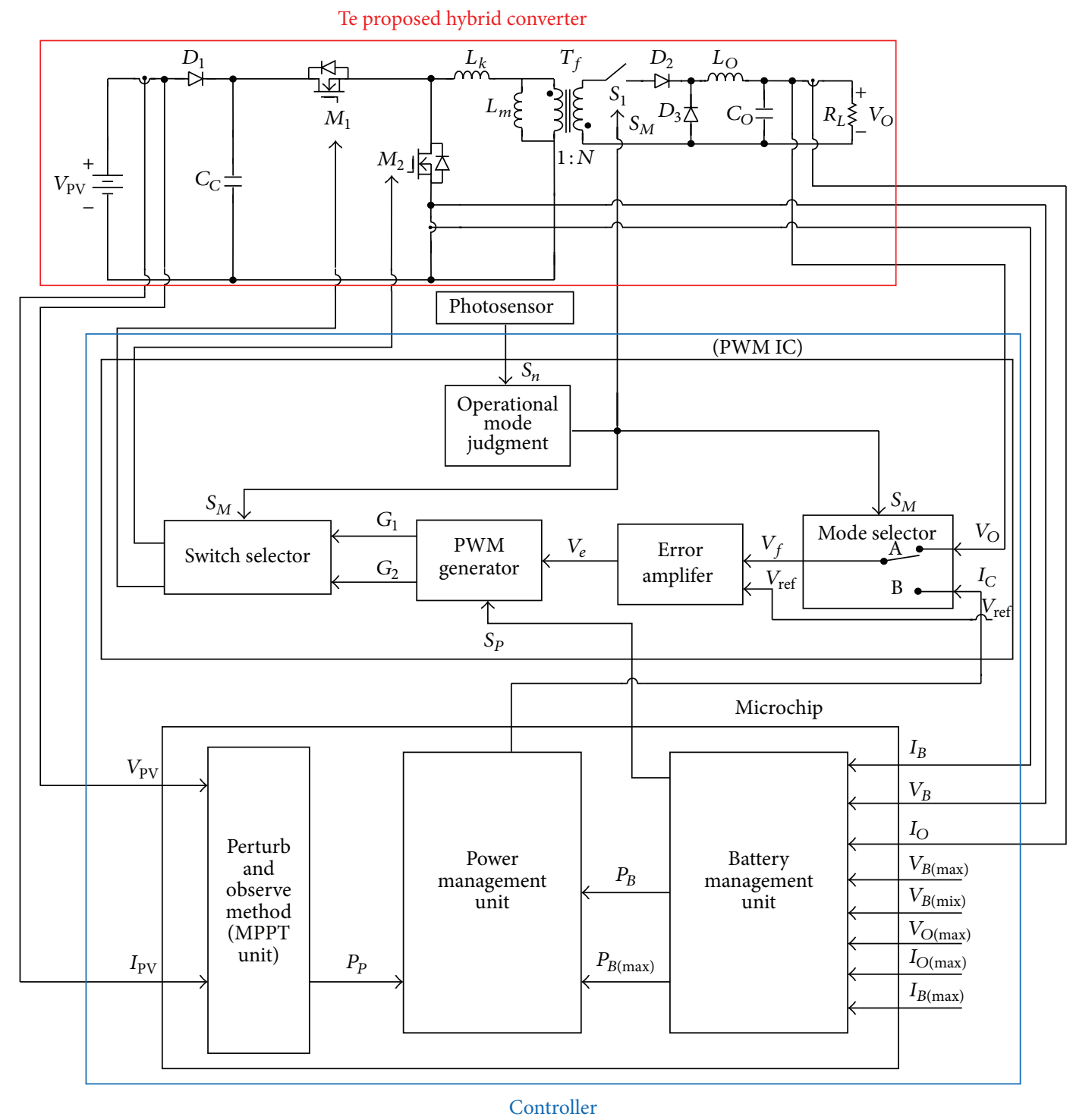

FIGURE 7: Block diagram of the proposed hybrid converter.

In the following, control algorithms for battery charging and LED driving are briefly described.

4.2.1. Battery Charging. Since the proposed hybrid converter supplies power to load from PV arrays, the proposed one must perform MPPT for PV arrays and battery charging for battery. The MPPT control method and battery charging method are described as follows.

MPPT Algorithm. Since solar cell has a lower output voltage and current, a number of solar cells are connected in series and parallel to form PV arrays for attaining the desired PV voltage and current. Their output characteristic variations depend on ambient temperature and insolation of sun. Figure 8 illustrates $P-V$ curve of $\mathrm{PV}$ arrays at different insolation of sun, from which it can be seen that each insolation level has a maximum power $P_{\max }$ where $P_{\max 1}$ is the most insolation of sun, while $P_{\max 3}$ is the one at the least insolation. Three maximum power point $P_{\max 1} \sim P_{\max 3}$ can be connect by a straight line. The operational area is divided into two areas: A area and B area. When operational point of PV arrays locates in A area, output current $I_{\mathrm{PV}}$ of PV arrays is decreased to make the operational point close to its maximum power point (MPP). If operational point is set in B area, current $I_{\mathrm{PV}}$ will be increased to operate PV arrays at its MPP.

The proposed power system adopts perturb and observe method to implement MPPT. Its flowchart is shown in Figure 9. In Figure 9, $V_{n}$ and $P_{p}$ separately represent their old voltage and power, and $P_{n}\left(=V_{n} I_{n}\right)$ is its new power. According to flowchart procedures of MPPT using perturb and observe method, first step is to read new voltage $V_{n}$ and current $I_{n}$ of PV arrays and then to calculate new PV power $P_{n}$. Next step is to judge relationship of $P_{n}$ and $P_{p}$. Since the relationship of $P_{n}$ and $P_{p}$ has three different relationships, they are separately 


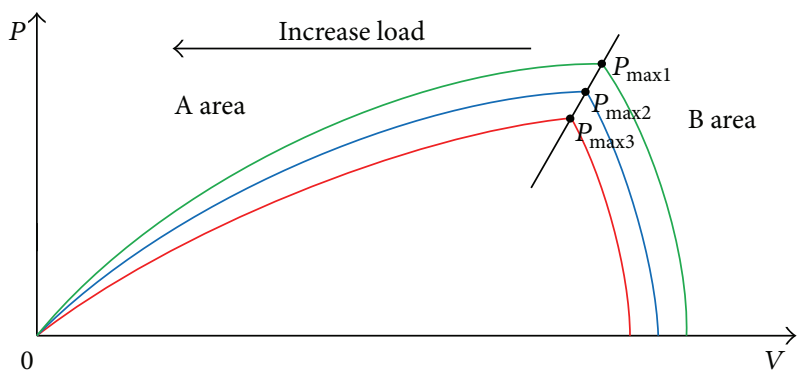

Figure 8: Plot of $P-V$ curve for PV arrays at different isolation of sun.

$P_{n}>P_{p}, P_{n}=P_{p}$, and $P_{n}<P_{p}$. Each relationship can be corresponded to the different relationship of $V_{n}$ and $V_{p}$. Therefore, when the relationship of $P_{n}$ and $P_{p}$ is decided, next step is to find the relationship of $V_{n}$ and $V_{p}$. According to the relationship of $P-V$ curve of PV arrays, when the relationships of $P_{n}$ and $P_{p}$ and $V_{n}$ an $V_{p}$ are decided, working point of PV arrays can be specified. When working point of PV arrays locates in A area, power system connected in PV arrays to supply load power must decrease output power to close the distance between working point and MPP of PV arrays. On the other hand, when working point sets in B area, power system must increase output power to make working point to approach MPP of PV arrays. Finally, $V_{p}$ is replaced by $V_{n}$ and $P_{p}$ is also substituted by $P_{n}$. The procedure of flowchart returns first step to judge next working point of PV arrays. Moreover, when $P_{n}=P_{P}$ and $V_{n}=V_{P}$, working point of $\mathrm{PV}$ arrays set in the MPP of PV arrays. The maximum power $P_{P}$ of PV arrays is transferred to power management unit for regulating power of battery charging.

Battery Charging Method. The proposed hybrid converter uses CC charging method to charge battery. According to battery specifications, charging voltage and current are limited for extending its life cycle. Therefore, the power limitation curve for battery charger will be limited. Figure 10 depicts conceptual waveforms of charging current, voltage, and power for battery charger with CC charging method. The battery charging time is from $T_{0}$ to $T_{c}$. When $t=T_{0}$, the proposed power system begins to charge battery and battery voltage $V_{B}$ is at the minimum value $V_{B(\min )}$. When $t=T_{c}$, battery is charged to its maximum voltage $V_{B(\max )}$. According to limitation of the maximum battery charging current $I_{B(\max )}$, power limitation curve of battery charging can be determined from $T_{0}$ to $T_{c}$. The charging power of battery follows the power limitation curve for extending its life cycle.

Since power limitation curve of battery has upper and lower values, they are, respectively, $P_{B(\min )}\left(=V_{B(\min )} I_{B(\max )}\right)$ and $P_{B(\max )} \quad\left(=V_{B(\max )} I_{B(\max )}\right)$. According to relationship among $P_{\mathrm{PV}(\max )}, P_{B(\min )}$, and $P_{B(\max )}$, they can be divided into three operational states: $P_{\mathrm{PV}(\max )}<P_{B(\min )}, P_{B(\min )} \leq$ $P_{\mathrm{PV}(\max )}<P_{B(\max )}$, and $P_{\mathrm{PV}(\max )}>P_{B(\max )}$, as shown in Figure 11. When $P_{\mathrm{PV}(\max )}<P_{B(\min )}$, power curve of battery charging follows $P_{\mathrm{PV}(\max )}$. When $P_{B(\min )} \leq P_{\mathrm{PV}(\max )}<P_{B(\max )}$, power limitation curve and $P_{\mathrm{PV}(\max )}$ intersects at $\mathrm{A}$ point where its intersecting time is $T_{A}$. Power curve tracks power limitation curve before $t=t_{A}$, while it traces $P_{\mathrm{PV}(\max )}$ after $t=$ $t_{A}$, as shown in Figure 11(b). If operational state of $P_{\mathrm{PV}(\max )}>$ $P_{B(\max )}$, power curve is regulated by power limitation curve, as shown in Figure 11(c). As mentioned above, battery charging can be operated in a better charging mode.

In order to implement a better battery charging, power management and battery management units are adopted and they are implemented by microchip. In the following, power management and battery management are briefly described.

(1) Power Management. In Figure 7, the controller includes microchip and PWM IC. When the microchip is used to execute power management, its control procedures are depicted in Figure 12. First step is to set $S_{P}=0$ and then is to read control signals. The control signals include $V_{O(\max )}, V_{B(\max )}, V_{B(\min )}, V_{B}, I_{B}, I_{B(\max )}, I_{O}, I_{O(\max )}, V_{\text {ref }}$, and $P_{P}$. When control signals are obtained by microchip, next step is to calculate $P_{B(\max )}\left(=V_{B} I_{B(\max )}\right)$ and $P_{B}\left(=V_{B} I_{B}\right)$. Since $P_{P}$, which is attained by MPPT control method, is the maximum output power of $\mathrm{PV}$ arrays, when $P_{P} \geq P_{B(\max )}$ is confirmed, $P_{\text {set }}$ is set to equal $P_{B(\max )}$. If $P_{P} \geq P_{B(\max )}$ is denied, $P_{\text {set }}=P_{P}$. The $P_{P}$ is the power command of battery charging. Therefore, power error value $\Delta P$ can be determined. It is equal to $\left(P_{\text {set }}-P_{B}\right)$. When $\Delta P$ is determined, current command $I_{C}$ can be obtained. It is equal to $\left(\Delta P / V_{B}\right)$. The current command $I_{C}$ is sent to PWM IC to determine gate signals $G_{1}$ and $G_{2}$. Next step is to judge next current command.

(2) Battery Management. In Figure 12, the right hand side of flowchart shows procedures of battery management. When the microchip reads control signals, the procedure of battery management is to judge overcurrent condition. When $I_{O} \geq$ $I_{O(\max )}$ is confirmed, overcurrent condition of the proposed hybrid converter occurred. When overcurrent condition occurred, signal $S_{P}$ is set to 1 . The $S_{P}$ is sent to PWM IC to shutdown PWM generator and the proposed hybrid converter is also shutdown. Next step is to judge next current command. Moreover, when $V_{O} \geq V_{O(\max )}$ (overcharge condition), $V_{B} \leq V_{B(\min )}$ (undercharge condition) and $V_{B} \geq$ $V_{B(\max )}$ (overcharge condition), the control procedure enters to set $S_{P}=1$ and to shutdown the proposed hybrid converter. According to previously describing procedures, battery can be properly controlled to complete a better charging condition.

(3) PWM IC. In the battery charging mode, PWM IC is used to control charging current with CC method. First, photosensor is used to detect insolation level of sun. When insolation is a high level, $S_{n}=0$. If insolation is a low level, $S_{n}=1$. The signal $S_{n}$ is sent to operational mode judgment to obtain mode control signal $S_{M}$. When $S_{M}=0$, the hybrid converter enters battery charging mode. That is, the insolation of sun is at a high level and $S_{n}=0$. If $S_{M}=1$, the one is in LED driving mode. The signal $S_{n}=1$ and insolation is at a low level. The mode control signal $S_{M}$ is sent to mode selector, switch selector, and switch $S_{1}$. When mode selector 


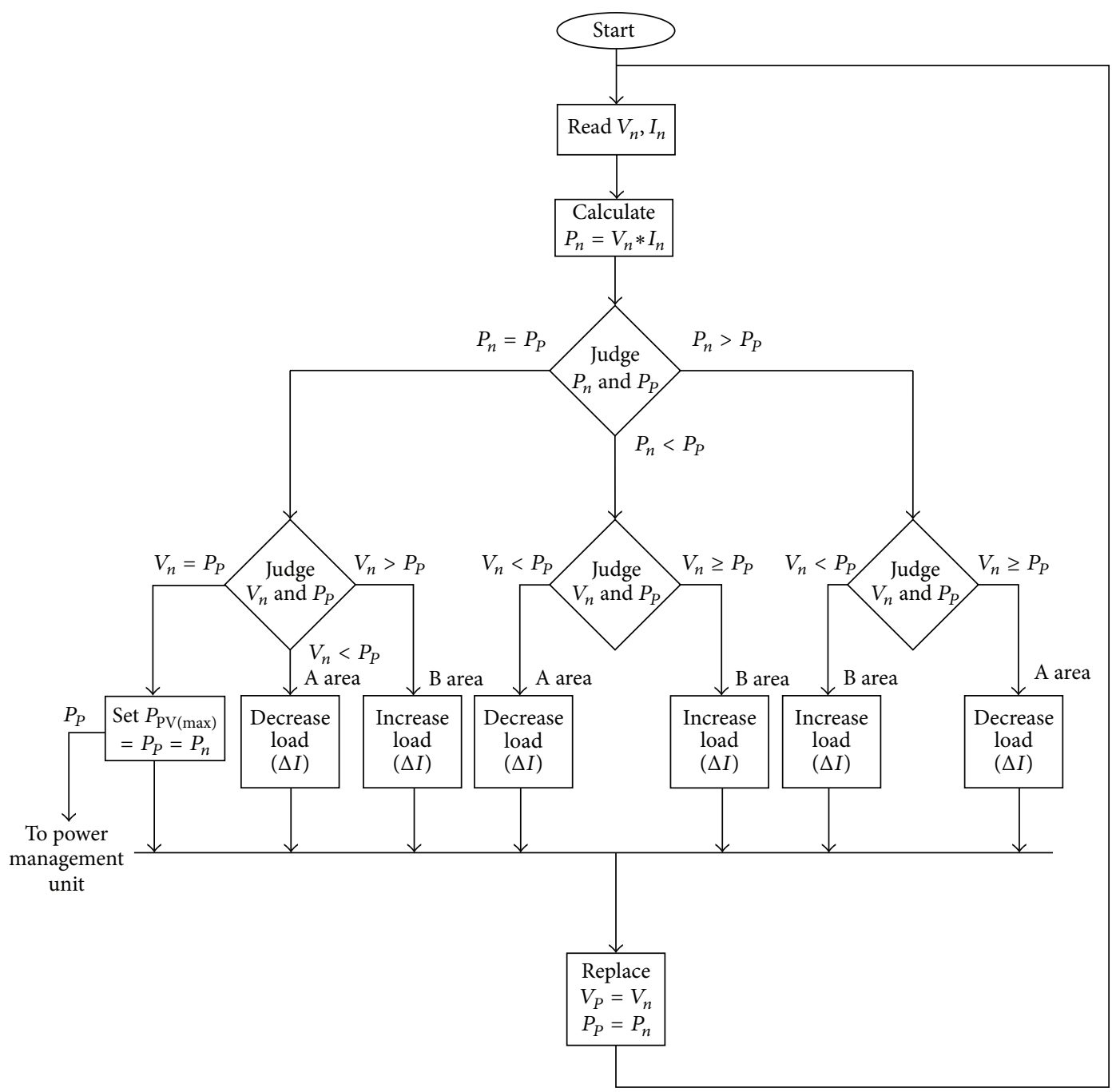

FIGURE 9: Flowchart of MPPT using perturb and observe method for PV arrays system.

receives $S_{M}=0$, the feedback signal $V_{f}$ is set to equal IC. The feedback signal $V_{f}$ and reference single $V_{\text {ref }}$ are sent to error amplifier to obtain error value $V_{e}$. When error value $V_{e}$ is attained, PWM generator can depend on $V_{e}$ to determine duty ratios of PWM signals $G_{1}$ and $G_{2}$. When $G_{1}$ and $G_{2}$ are specified and $S_{M}=0$, switch selector can set that $M_{1}=G_{1}$ and $M_{2}=G_{2}$ to control the charging current $I_{B}$ of battery. As mentioned above, the proposed hybrid converter can use microchip and PWM IC to achieve battery charging.

4.2.2. LED Driving. The LED driving mode is regarded as battery discharging mode. When operational mode enters LED driving mode, $S_{M}=1$. The mode selector can be operated to set $V_{f}=V_{O}$. The $V_{f}$ and $V_{\text {ref }}$ are sent to error amplifier to attain $V_{e}$. The $V_{e}$ is through PWM generator to generate signals $G_{1}$ and $G_{2}$. Since $S_{M}=1$, switch selector is controlled by $S_{M}$ to set $M_{1}=G_{2}$ and $M_{2}=G_{1}$. Therefore, the proposed hybrid converter can depend on duty ratios of gate signals $M_{1}$ and $M_{2}$ to supply power to LED until battery voltage $V_{B}$ is equal to or less than $V_{B(\min )}$. When $V_{B} \leq V_{B(\min )}$, the proposed hybrid converter is shutdown.

\section{Experimental Results}

In order to verify the circuit analysis and component design of the proposed power system, a prototype, which is composed of a charger and LED driving circuit (discharger), with the following specifications was implemented.

\subsection{Buck-Boost Converter (Charger)}

(i) Input voltage $V_{\mathrm{PV}}$ : DC $17 \mathrm{~V} \sim 21 \mathrm{~V}$ (PV arrays)

(ii) Switching frequency $f_{s 1}: 250 \mathrm{KHz}$

(iii) Output voltage $V_{B}$ : DC $5 \sim 7 \mathrm{~V}$ (lead-acid battery: $6 \mathrm{~V} / 2.3 \mathrm{Ah})$

(iv) Maximum output current $I_{B(\max )}: 2.3 \mathrm{~A}$. 


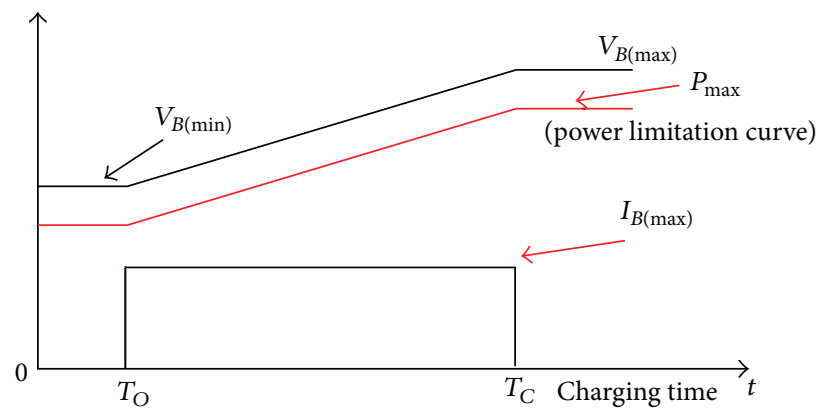

FIGURE 10: Conceptual waveforms of charging current, voltage, and power for battery charger with CC charging method.

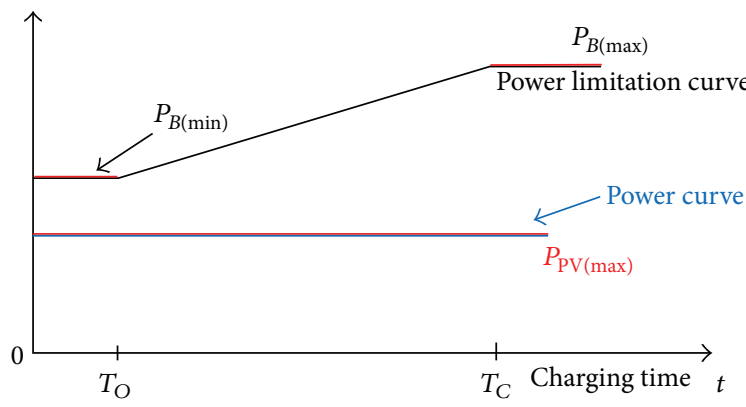

(a) $P_{\mathrm{PV}(\max )}<P_{B(\min )}$

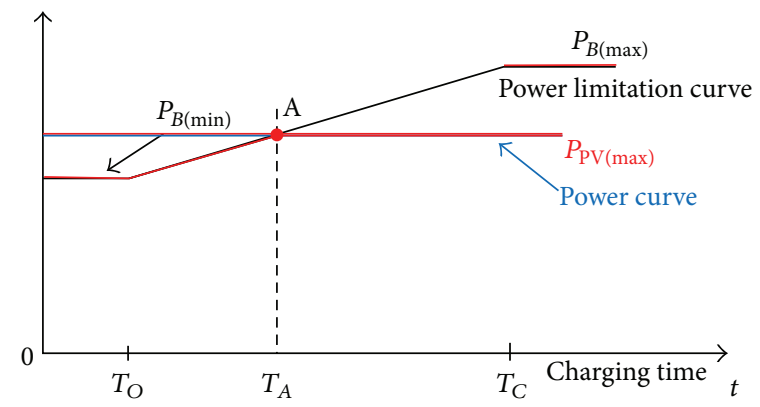

(b) $P_{B(\min )} \leq P_{\mathrm{PV}(\max )}<P_{B(\max )}$



(c) $P_{\mathrm{PV}(\max )}>P_{B(\max )}$

FIGURE 11: Conceptual waveforms of maximum output power of PV arrays and power limitation and power curves of battery from $T_{O}$ to $T_{C}$ : (a) $P_{\mathrm{PV}(\max )}<P_{B(\min )}$, (b) $P_{B(\min )} \leq P_{\mathrm{PV}(\max )}<P_{B(\max )}$, and (c) $P_{\mathrm{PV}(\max )}>P_{B(\max )}$.

\subsection{Active Clamp Forward Converter (LED Driving Circuit)}

(i) Input voltage $V_{B}:$ DC $5 \mathrm{~V} \sim 7 \mathrm{~V}$

(ii) Switching frequency $f_{s 2}: 250 \mathrm{KHz}$

(iii) Output voltage $V_{\mathrm{O}}: \mathrm{DC} 10 \mathrm{~V}$

(iv) Maximum output current $I_{\mathrm{O}(\max )}: 2 \mathrm{~A}$.

According to previously specifications and design of the hybrid converter, inductors $L_{2}$ and $L_{m}$ and capacitor $C_{C}$ can be determined. In (17) illustrated in [23], since inductor $L_{m}$ must be greater than $7.09 \mathrm{uH}$ under $V_{O}=10 \mathrm{~V}, V_{B}=7 \mathrm{~V}$, and $V_{\mathrm{PV}}=17 \mathrm{~V}, L_{2}$ is chosen by $40 \mathrm{uH}$. According to (6) and (22) illustrated in [23], the magnetizing inductor $L_{m}$ must be greater than $6.8 \mathrm{uH}$ under $N=5, V_{B}=7 \mathrm{~V}$, and $L_{2}=$ $40 \mathrm{uH}$. Therefore, magnetizing inductor $L_{m}$ is determined by $40 \mathrm{uH}$, while its leakage inductor $L_{K}$ is obtained by $0.2 \mathrm{uH}$. Moreover, capacitor $C_{C}$ can be attained by (29) illustrated in [23]. Its capacitance $C_{C}$ is $0.22 \mathrm{nF}$ under $N=5$ and $V_{B}=7 \mathrm{~V}$. Therefore, $C_{C}$ is chosen by $0.24 \mathrm{uF}$. The components of power stage in the proposed hybrid converter was determined as follows:

(i) switches $M_{1}, M_{2}$ : PSMN005-75B,

(ii) diodes $D_{1}, D_{2}$ : UF601,

(iii) transformer $T_{f}$ : EE-25 core,

(iv) inductor $L_{2}$ : EE-22 core, 


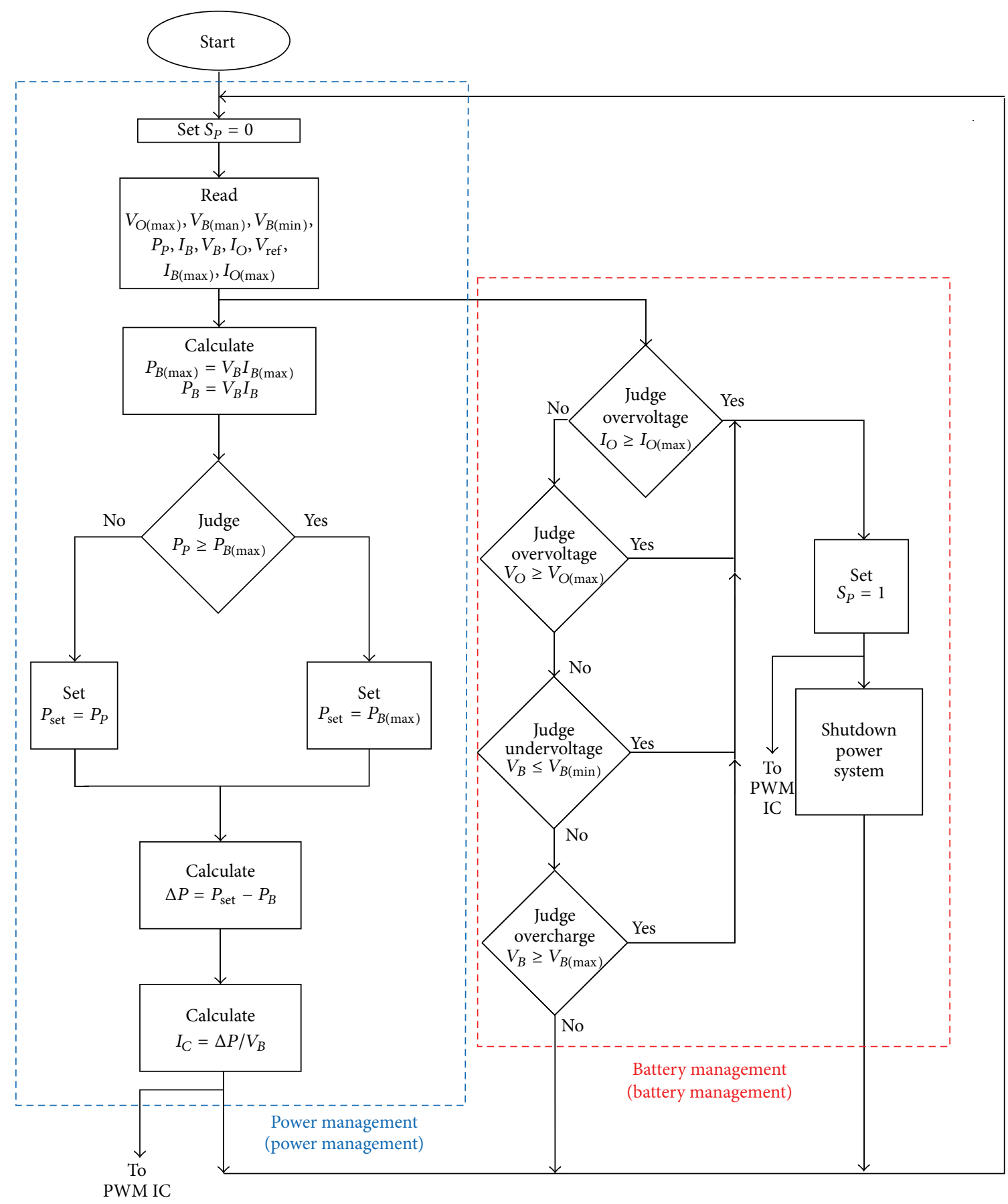

FIGURE 12: Flowchart of power and battery managements of the proposed hybrid converter.

(v) capacitor $C_{O}: 47 \mu \mathrm{F} / 25 \mathrm{~V}$, and

(vi) switch $S_{1}$ : IRFP540.

Since the charging current $I_{B}$ of battery can be varied by duty ratio of switch $M_{1}$ in buck-boost converter, its value is proportional to duty ratio $D_{11}$. Figures $13(\mathrm{a})$ and $13(\mathrm{~b})$, respectively, depict the measured voltage $V_{D S}$ waveform of switch $M_{1}$ and current $I_{B}$ waveform under duty ratio of
0.31 and 0.35 , illustrating that the charging current $I_{B}$ can be increased by duty ratios increase. Measured waveforms of PV arrays current $I_{\mathrm{PV}}$ and voltage $V_{\mathrm{PV}}$ using the perturb and observe method are illustrated in Figure 14. Figure 14(a) illustrates the MPP of PV arrays at 10 W, while Figure 14(b) depicts that at $20 \mathrm{~W}$. Figure 15 shows the measured battery voltage $V_{B}$ and current $I_{B}$ under MPP of PV arrays at $10 \mathrm{~W}$, from which it can be found that the maximum charging 




$\left(V_{D S}: 25 \mathrm{~V} / \mathrm{div}, I_{D S}: 500 \mathrm{~mA} / \mathrm{div}, 1 \mu \mathrm{s} / \mathrm{div}\right)$

(a)

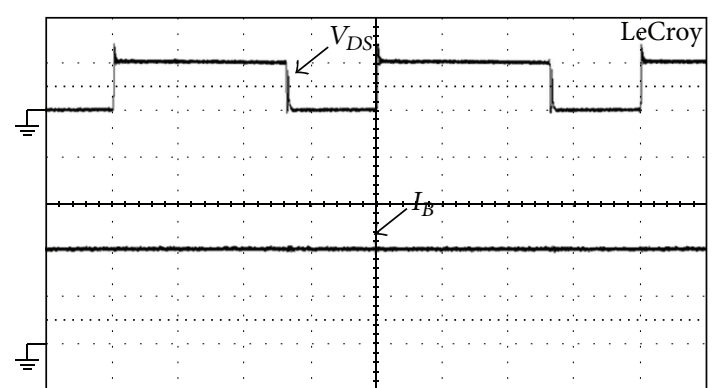

$\left(V_{D S}: 25 \mathrm{~V} / \operatorname{div}, I_{D S}: 500 \mathrm{~mA} / \mathrm{div}, 1 \mu \mathrm{s} / \mathrm{div}\right)$

(b)

FIGURE 13: Measured voltage $V_{D S}$ waveform of switch $M_{1}$ and the charged current $I_{B}$ waveform operated in duty ratio of (a) 0.31 and (b) 0.35 for working in the charging state.

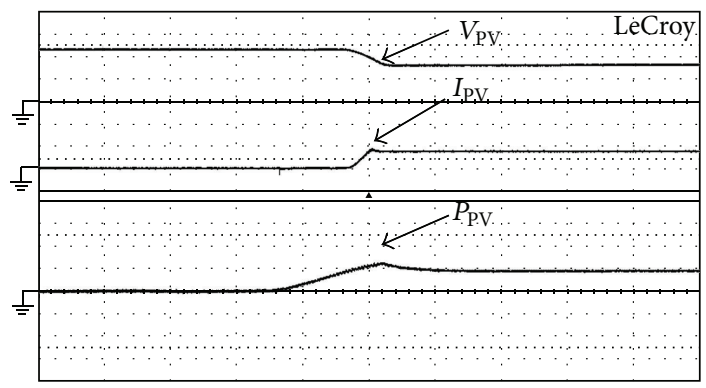

$\left(V_{\mathrm{PV}}: 20 \mathrm{~V} / \mathrm{div}, I_{\mathrm{PV}}: 2 \mathrm{~A} / \mathrm{div}, P_{\mathrm{PV}}: 50 \mathrm{~W} / \mathrm{div}\right.$, time: $\left.100 \mathrm{~ms} / \mathrm{div}\right)$

(a)

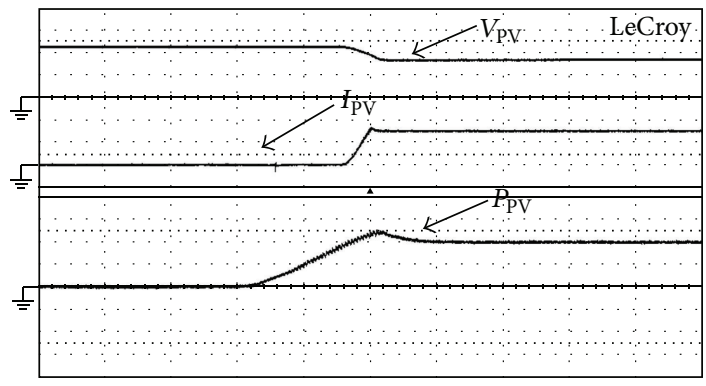

$\left(V_{\mathrm{PV}}: 20 \mathrm{~V} / \mathrm{div}, I_{\mathrm{PV}}: 2 \mathrm{~A} / \mathrm{div}, P_{\mathrm{PV}}: 50 \mathrm{~W} / \mathrm{div}\right.$, time: $\left.100 \mathrm{~ms} / \mathrm{div}\right)$

(b)

FIGURE 14: Measured voltage $V_{\mathrm{PV}}$, current $I_{\mathrm{PV}}$, and power $P_{\mathrm{PV}}$ waveforms of PV arrays using the perturb and observe method to track MPPT of arrays (a) under $P_{\mathrm{PV}(\max )}=10 \mathrm{~W}$ and (b) under $P_{\mathrm{PV}(\max )}=20 \mathrm{~W}$.

current $I_{B}$ is limited at 1.5 A under battery voltage $V_{B}$ of $6.5 \mathrm{~V}$ due to control of power management.

When the proposed hybrid converter is operated in the discharging state (LED driving state), active clamp forward is in working. Measured voltage $V_{D S}$ and current $I_{D S}$ waveforms of switched $M_{1}$ and $M_{2}$ are, respectively, illustrated in Figures 16 and 17. Figures 16(a) and 16(b) show those waveforms under $20 \%$ of full load, while Figures 17 (a) and 17(b) depict those waveforms under full load. From Figures 16 and 17, it can be seen that switches $M_{1}$ and $M_{2}$ are operated with ZVS

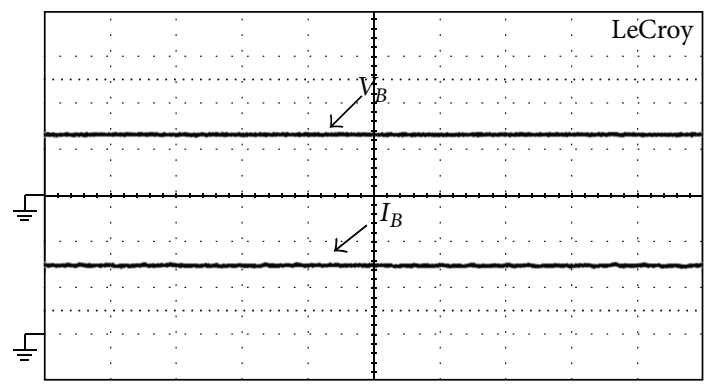

$\left(V_{B}: 5 \mathrm{~V} / \mathrm{div}, I_{B}: 1 \mathrm{~A} / \mathrm{div}\right.$, time: $\left.10 \mathrm{~ms} / \mathrm{div}\right)$

FIGURE 15: Measured battery voltage $V_{B}$ and current $I_{B}$ waveforms under $P_{\mathrm{PV}(\max )}=10 \mathrm{~W}$.

at turn-on transition. Comparison of conversion efficiency between forward converter with hard-switching circuit and with the proposed active clamp circuit from light load to heavy load is depicted in Figure 18, from which it can be found that the efficiency of the proposed converter is higher than that of hard-switching one. Its maximum efficiency is $90 \%$ under $80 \%$ of full load and its efficiency is $83 \%$ under full load. Figure 19 illustrates step-load change between $20 \%$ of full load and full load, illustrating that the voltage regulation $V_{\mathrm{O}}$ has been limited within $\pm 2 \%$. From experimental results, it can be found that the proposed hybrid converter is suitable for electronic sign applications.

\section{Conclusion}

In this paper, the buck-boost converter combined with active clamp forward converter to form the proposed hybrid converter is used to implement battery charger and driving LED. Circuit derivation of the hybrid converter with switch integration technique is presented in this paper to reduce component counts. Operational principle, steadystate analysis, and design of the proposed hybrid converter have been described in detail. From efficiency comparison between forward converter with hard-switching circuit and with the proposed active clamp circuit, the proposed active clamp converter can yield higher efficiency. An experimental 


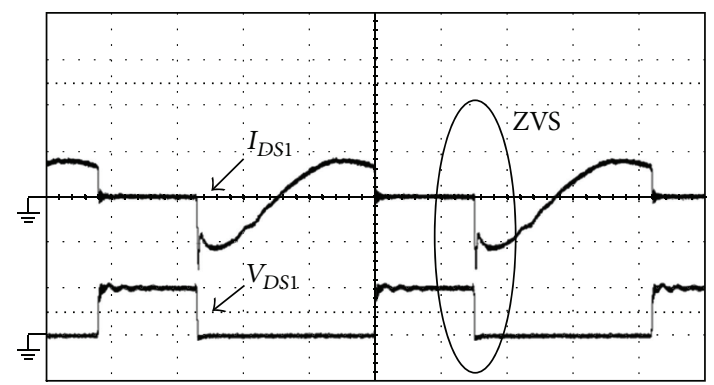

$\left(V_{D S 1}: 10 \mathrm{~V} / \mathrm{div}, I_{D S 1}: 4 \mathrm{~A} / \mathrm{div}, 1 \mu \mathrm{s} / \mathrm{div}\right)$

(a)

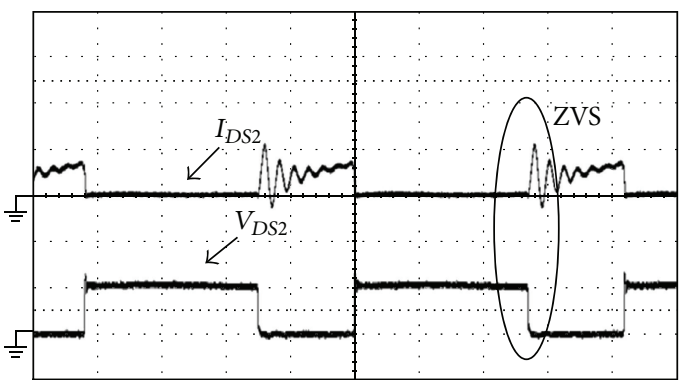

$\left(V_{D S 2}: 10 \mathrm{~V} / \mathrm{div}, I_{D S 2}: 4 \mathrm{~A} / \mathrm{div}, 1 \mu \mathrm{s} / \mathrm{div}\right)$

(b)

FIGURE 16: Measured voltage $V_{D S}$ and current $I_{D S}$ waveforms of (a) switch $M_{1}$ and (b) switch $M_{2}$ for working under $20 \%$ of full load.

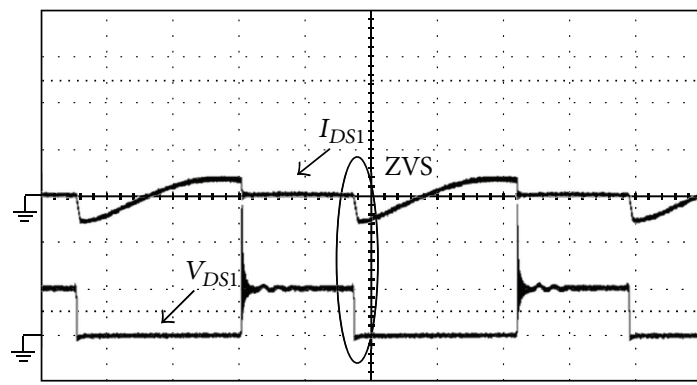

$\left(V_{D S 1}: 10 \mathrm{~V} / \mathrm{div}, I_{D S 2}: 15 \mathrm{~A} / \mathrm{div}, 1 \mu \mathrm{s} / \mathrm{div}\right)$

(a)



$\left(V_{D S 2}: 10 \mathrm{~V} / \mathrm{div}, I_{D S 2}: 15 \mathrm{~A} / \mathrm{div}, 1 \mu \mathrm{s} / \mathrm{div}\right)$

(b)

FIGURE 17: Measured voltage $V_{D S}$ and current $I_{D S}$ waveforms of (a) switch $M_{1}$ and (b) switch $M_{2}$ for working under full load.

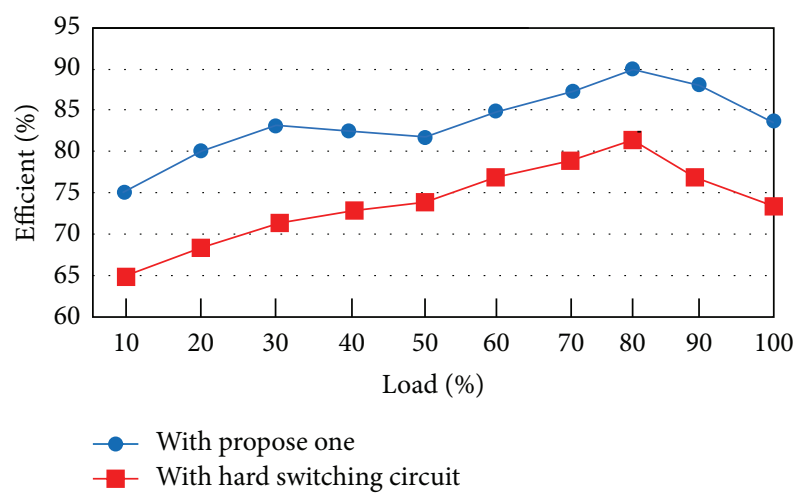

FIGURE 18: Comparison conversion efficiency between the conventional hard-switching forward converter and the proposed one from light load to heavy load for working in the discharging state.

prototype for a battery charger for lead-acid battery of $6 \mathrm{~V} / 2.3 \mathrm{Ah}$ and discharger for LED driving under $10 \mathrm{~V} / 2 \mathrm{~A}$ has been built and evaluated, achieving the maximum efficiency of $90 \%$ under $80 \%$ of full load and verifying the feasibility of the proposed hybrid converter. Moreover, constant current charging method, MPPT with perturb and observe method, and power management have been implemented by microchip and PWM IC.

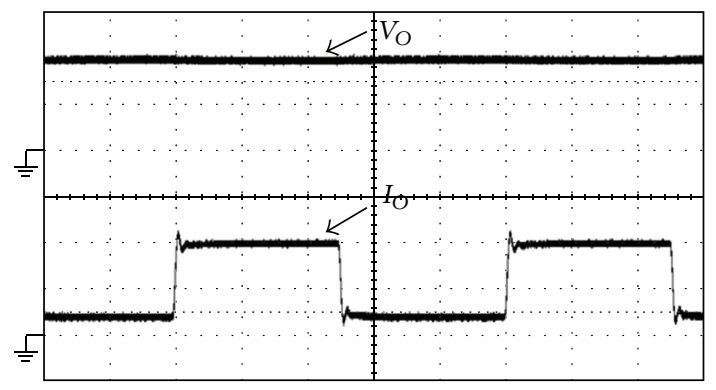

$\left(V_{O}: 5 \mathrm{~V} / \mathrm{div}, I_{O}: 1 \mathrm{~A} / \mathrm{div}, 500 \mu \mathrm{s} / \mathrm{div}\right)$

FIgURE 19: Output voltage $V_{O}$ and output current $I_{O}$ under step-load charges between $30 \%$ and $100 \%$ of full load of the proposed forward converter operated in the discharging state.

\section{Conflict of Interests}

The authors declare that there is no conflict of interests regarding the publication of this paper.

\section{References}

[1] Y. Jiang, A. W. Leung, J. Xiang, and C. Xu, "LED light-activated hypocrellin B induces mitochondrial damage of ovarian cancer cells," International Journal of Photoenergy, vol. 2012, Article ID 186752, 5 pages, 2012. 
[2] C.-H. Liu, C.-Y. Hsieh, Y.-C. Hsieh, T.-J. Tai, and K.-H. Chen, "SAR-controlled adaptive off-time technique without sensing resistor for achieving high efficiency and accuracy LED lighting system," IEEE Transactions on Circuits and Systems I, vol. 57, no. 6, pp. 1384-1394, 2010.

[3] C. C. Chen, C.-Y. Wu, and T.-F. Wu, "LED back-light driving system for LCD panels," in Proceedings of The Applied Power Electronics Conference and Exposition, pp. 19-23, 2006.

[4] S.-Y. Tseng and C.-T. Tsai, "Photovoltaic power system with an interleaving boost converter for battery charger applications," International Journal of Photoenergy, vol. 2012, Article ID 936843, 15 pages, 2012.

[5] J.-H. Park and B.-H. Cho, "Nonisolation soft-switching buck converter with tapped-inductor for wide-input extreme stepdown applications," IEEE Transactions on Circuits and Systems I, vol. 54, no. 8, pp. 1809-1818, 2007.

[6] K. Mehran, D. Giaouris, and B. Zahawi, "Stability analysis and control of nonlinear phenomena in boost converters using model-based Takagi-Sugeno fuzzy approach," IEEE Transactions on Circuits and Systems I, vol. 57, no. 1, pp. 200-212, 2010.

[7] B. Bryant and M. K. Kazimierczuk, "Open-loop power-stage transfer functions relevant to current-mode control of boost PWM converter operating in CCM," IEEE Transactions on Circuits and Systems I, vol. 52, no. 10, pp. 2158-2164, 2005.

[8] M. R. Yazdani, H. Farzanehfard, and J. Faiz, "EMI analysis and evaluation of an improved ZCT flyback converter," IEEE Transactions on Power Electronics, vol. 26, no. 8, pp. 2326-2334, 2011.

[9] K. I. Hwu and T. J. Peng, "A novel buck-boost converter combining KY and buck converters," IEEE Transactions on Power Electronics, vol. 27, no. 5, pp. 2236-2241, 2012.

[10] F. Xie, R. Yang, and B. Zhang, "Bifurcation and border collision analysis of voltage-mode-controlled flyback converter based on total ampere-turns," IEEE Transactions on Circuits and Systems I, vol. 58, no. 9, pp. 2269-2280, 2011.

[11] B.-R. Lin and H.-Y. Shih, "Implementation of a parallel zerovoltage switching forward converter with less power switches," IET Power Electronics, vol. 4, no. 2, pp. 248-256, 2011.

[12] D. Wang, X. He, and J. Shi, "Design and analysis of an interleaved flybackforward boost converter with the current autobalance characteristic," IEEE Transactions on Power Electronics, vol. 25, no. 2, pp. 489-498, 2010.

[13] T.-F. Wu and T.-H. Yu, "Unified approach to developing singlestage power converters," IEEE Transactions on Aerospace and Electronic Systems, vol. 34, no. 1, pp. 211-223, 1998.

[14] K. I. Hwu, W. C. Tu, and C. R. Wang, "Photovoltaic energy conversion system constructed by high step-up converter with hybrid maximum power point tracking," International Journal of Photoenergy, vol. 2013, Article ID 275210,, 9 pages, 2013.

[15] A. Braunstein and Z. Zinger, "On the dynamic optimal coupling of a solar cell array to a load and storage batteries," IEEE transactions on Power Apparatus and Systems, vol. 100, no. 3, pp. 1183-1188, 1981.

[16] A. S. Weddell, G. V. Merrett, and M. A.-H. Bashir, "Photovoltaic sample-and-hold circuit enabling MPPT indoors for low-power systems," IEEE Transaction on Circuits and Systems, vol. 59, no. 6, pp. 1196-1204, 2012.

[17] S. M. M. Wolf and J. H. R. Enslin, "Economical, PV maximum power point tracking regulator with simplistic controller," in Proceedings of the EEE 24th Annual Power Electronics Specialist Conference, pp. 581-587, June 1993.
[18] C.-L. Shen and S.-H. Yang, "Multi-input converter with MPPT feature for wind-PV power generation system," International Journal of Photoenergy, vol. 2013, Article ID 129254, 13 pages, 2013.

[19] R. Leyva, C. Olalla, H. Zazo et al., "MPPT based on sinusoidal extremum-seeking control in PV generation," International Journal of Photoenergy, vol. 2012, Article ID 672765, 7 pages, 2012.

[20] N. Onat, "Recent developments in maximum power point tracking technologies for photovoltaic systems," International Journal of Photoenergy, vol. 2010, Article ID 245316, 11 pages, 2010.

[21] K. H. Hussein, I. Muta, T. Hoshino, and M. Osakada, "Maximum photovoltaic power tracking: an algorithm for rapidly changing atmospheric conditions," IEE Proceedings: Generation, Transmission and Distribution, vol. 142, no. 1, pp. 59-64, 1995.

[22] S. R. Rajwade, K. Auluck, J. B. Phelps, K. G. Lyon, J. T. Shaw, and E. C. Kan, "A ferroelectric and charge hybrid nonvolatile memory-Part II: experimental validation and analysis," IEEE Transactions on Electron Devices, vol. 59, no. 2, pp. 450-458, 2012.

[23] S. Y. Tseng, H. Y. Wang, and C. C. Chen, "PV power system using hybrid converter for LED indictor applications," Energy Conversion and Management, vol. 75, pp. 761-772, 2013. 



\section{Carbohydrate} Chemistry



The Scientific World Journal
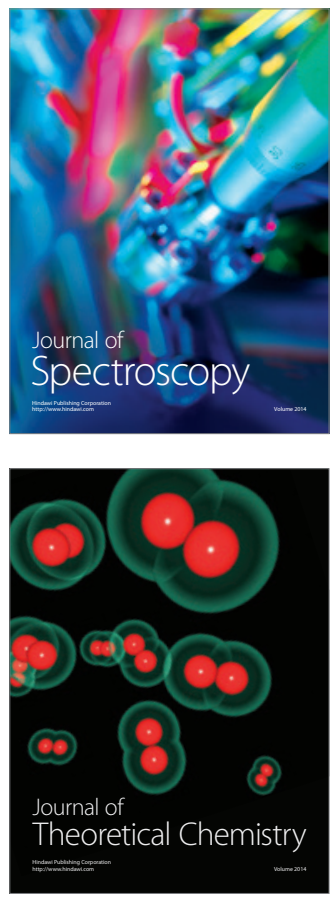


Submit your manuscripts at

http://www.hindawi.com



Analytical Methods

in Chemistry

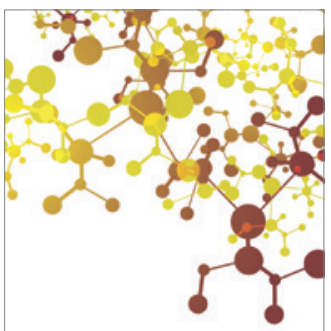

Journal of

Applied Chemistry



Inorganic Chemistry
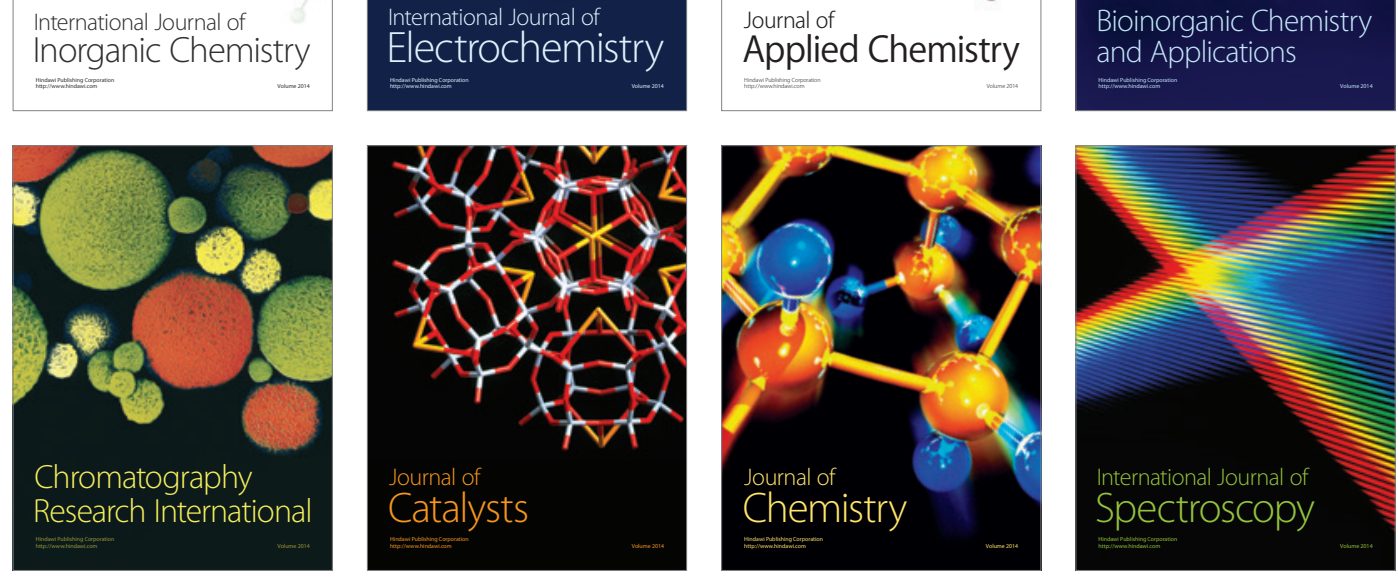